\title{
FATIGUE AND SLEEP QUALITY IN PATIENTS WITH EPILEPSY
}

\author{
Mukadder Mollaoglu ${ }^{1}$ and Yasemin Zeyrek $^{2}$ \\ ${ }^{1}$ Affiliation not available \\ ${ }^{2}$ Cumhuriyet Universitesi
}

May 7, 2020

\begin{abstract}
Purpose: In epilepsy patients, fatigue and sleep are among the important problems and they negatively affect the patient's quality of life. The purpose of the present study is to examine epilepsy patients' fatigue and quality of sleep. Method: The sample of this descriptive cross-sectional study consisted of 166 epilepsy patients undergoing outpatient treatment at a University Hospital Neurology Outpatient Clinic. In the study, Patient Information Form (PIF), Fatigue Severity Scale (FSS) and Pittsburg Sleep Quality Index (PSQI) were used in data collection. Data analysis was performed in SPSS 22.0 package program. Results: It was determined that the mean FSS in epilepsy patients was $4.44 \pm 1.72$. The mean PSQI was found to be $13.05 \pm 4.35$. While the relationship of patients' mean FSS scores with gender, and with the frequency of seizures in the recent year was found significant $(\mathrm{p}<0.05)$, the relationship of patients' mean PSQI scores with gender, marital status, the frequency of seizures, the presence of another disease other than epilepsy, the use of drugs other than antiepileptic drugs, and the number of drugs used, was also determined to be significant $(\mathrm{p}<0.005)$. In addition, a positive and statistically significant relationship was observed between FSS and PSQI $(\mathrm{p}<0.001)$. Conclusion: As a result, in the present study, patients with epilepsy were found to have a poor quality of sleep and the fatigue at the borderline. The data of the study demonstrates that the treatments and attempts to improve the quality of sleep also alleviate the fatigue of patients. For this reason, it is important to routinely handle sleep and fatigue problems of patients with epilepsy with a multidisciplinary approach and to develop effective approaches for their solution.
\end{abstract}

\section{Hosted file}

MANUSCRIPT.doc available at https://authorea.com/users/319366/articles/449090-fatigue-andsleep-quality-in-patients-with-epilepsy

\section{Hosted file}

TABLES.docx available at https://authorea.com/users/319366/articles/449090-fatigue-andsleep-quality-in-patients-with-epilepsy 